\title{
ADAPTIVITY OF BUFFALO CALVES TO DIFFER THERMAL CONDITIONS
}

\author{
SHAFIE ${ }^{1}$, M. M. and F. I. OMRAN ${ }^{2}$ \\ ${ }^{1}$ Department of Animal Production, Faculty of Agriculture, Cairo University, Giza, Egypt. \\ ${ }^{2}$ Animal Production Research Institute, Dokki, Giza, Egypt.
}

(Manuscript received 17 January 2018)

\begin{abstract}
$\mathrm{E}$ ight buffalo male calves, aged 6 months and average range weighed $118.00 \pm 2.6-119.25 \pm 2.2 \mathrm{~kg}$ were used in this study. The calves were divided into 2 comparative groups (A and $B$ ) with 4 calves each. The calves were exposed to either artificial constant severe heat stress (Lab A, $40^{\circ} \mathrm{C}$ ) or comfort (Lab $\mathrm{B}, 25^{\circ} \mathrm{C}$ ) for one month. The calves in both groups were then exposed to15 days period of natural climatic outdoors conditions. Thereafter the animals returned back to the same artificial condition. The average body weight at the end of exposure to heat stress before slaughter was $106.8 \pm 2.3$ for calves in group A and $167.0 \pm 3.2$ in group B (at 9 month of age). The calves were fasted for 19 hours before slaughter. After slaughter the skin was weighted. Then the skin samples were taken from the neck, abdomen and the back regions divided to 2 parts. One part was used to study the number of hairs by haircuts, weighed. And the counts relative to weight were determined. The development of acts in skin structure in response to heat regulating mechanism was also studied. The relationship between histological parameters (length, density, efficiency of tensor muscle of hair, thickness of skin, number of sweat glands and number of sebaceous glands), as well as the efficiency of buffalo under heat stress circumstances were also studied. The results indicated that the skin of animal plays an important role in adapting the animal under various conditions. High correlation ( $r=0.93, \mathrm{P} \leq 0.01)$ was found between animal body weight and skin weight in group $\mathrm{B}$. The correlation with hair in group $A$ was medium and negative $(r=-0.55, P \leq$ 0.01 ). The buffalo can change both morphology and histology of their skin to maintain biological processes within normal limits. Buffalo calves have the ability to modify their skin trout's to cope with a wide variety of thermal conditions. This modification includes changes in skin thickness, hair length, number of hair follicles and hair color. The great adaptive potentiality of buffalo to heat stress condition makes the animals of choice to live successfully under the circumstances of the upcoming climatic changes.
\end{abstract}

Keywords: Buffaloes, skin, histology, morphology, thermal condition.

\section{INTRODUCTION}

The body coat of an animal plays a major role in adaptation and production under climatic condition (Hafez et al., 1955). The morphological characteristics of hair coat are markedly influenced by climate. In the temperate zone, cattle have long, dark 
colored and non-glossy hairs. In the tropics and subtropics, the indigenous cattle have short, glossy hairs ranging in Coburn from grey to fawn and yellow (Hafez et al., 1955). Collier et al (2006) found that, the skin temperature was highly correlated with respiration rates and being a good measure of microenvironment around the animals. Moreover, if the skin surface temperature is below $35^{\circ} \mathrm{C}$, the temperature gradient between the core and skin is large enough for the animals to effectively use all routes of heat exchange. The wide range of environmental temperatures that comprise the thermo-neutral zone animals maintain their heat balance of the rough vasomotor control by regulating the amount of blood flowing through the coetaneous vessels by either vasodilation or vasoconstriction. Vasodilation stimulates the pilomotor center to flatten the hair cover to allow better heat dissipation through sensible means. In addition loss from the surface of the body because of diffusion of water through the skin as in sensible perspiration. Color, length, density, efficiency of tensor muscle for hair and the thickness number of sweat glands in the skin differ between animals (Hafez et al., 1955b). The morphological, anatomical and physiological characteristics of buffalo give more suitability to hot conditions (Shafie, 1958; 1985; 1993a and 1993b). The size and surface area of an animal's body show special adaptation to environmental factors. The extent of heat exchange between an animal and its surrounding depends partly on body surface area, resulting in the metabolic rate of an animal being routinely expressed in term of kilocalories per square meter of body surface per hour.

Studies on buffalo skin are little. This investigation was designed to study the changes acts in skin structure in relation to body heat regulation. The relationship between histological tracts of skin length, density, efficiency of tensor muscle of hair, thickness of skin, and number of sweat gland, number of sebaceous gland with the efficiency the buffalo under heat stress conditions was also studied.

\section{MATERIALS AND METHODS}

This study was carried out at the experimental farm and the Animal Physiology Research Lab, Animal Production Department, Faculty of Agriculture, Cairo University, Giza, Egypt. Eight buffalo calves (Bubalus bubalis) belonging to Mahalet Mousa Experimental Farm, Animal Production Research Institute, Agriculture Research Center, Ministry of Agriculture, Egypt were available to this study.

At the start of the experiment, eight buffalo calves aging $6.00 \pm 0.10$ months with an average body weight of $118.63 \pm 2.3 \mathrm{~kg}$ were divided into two groups ( $A$ and $B, 4$ calves in each lab). The calves were exposed to either artificial thermal constant severe heat stress $\left(\operatorname{Lab} A, 40^{\circ} \mathrm{C}\right.$ ) and comfort conditions (Lab $B, 25^{\circ} \mathrm{C}$ ) for one 
month, then interrupted by 15 days period under natural climatic outdoors conditions, thereafter for an additional one month under the same artificial conditions.

The lab (A) involved 4 highly sensitive digital thermostat heaters alongside ceiling and equipped with suction fans (controlled Lab A).. Thus the ambient temperature (AT, ${ }^{\circ} \mathrm{C}$ ) in this lab was fixed and maintained exactly at $40^{\circ} \mathrm{C}$. The relative humidity $(\mathrm{RH}$, $\%$ ) was $87.3-87.7 \%$ and the temperature-humidity indices (THI) was 101.2 \pm 0.1 , $100.0 \pm 0.1$ for the $1^{\text {st }}$ and $2^{\text {nd }}$, respectively. Lab (B) was adjusted to $25^{\circ} \mathrm{C}$; the RH at 61.3 - $67.9 \%$. The temperature-humidity indices (THI) were $74.0 \pm 0.3,75.0 \pm 0.6$ for $1^{\text {st }}$ and $2^{\text {nd }}$, respectively. Animals were fed a concentrate starter ration during the first month of experimentation (6-7 months old), then a growing concentrate until the end of experimental work at the $9^{\text {th }}$ month of age.

The roughage feeds included wheat straw and Berseem hay (according to NRC, 1981). The average body weight at the end of the exposure to heat stress, just before slaughtered was $106.8 \pm 5.6 \mathrm{Kg}$ for calves in-group $\mathrm{A}$ and $167.0 \pm 4.2 \mathrm{Kg}$ ingroup B (at 9 month of age). Calves stayed in labs under above conditions until slaughter. Calves were fasted 19 hours before slaughter. After slaughter, the skin was removed, weighed and samples were then taken from the parts to the direction of the neck skin, abdomen and the back of the animal and divided into two parts. One part was used for studding number of hair by haircuts then weighed, and sample of the hair was taken and the total attributed to the weight were estimated, the sample was $2 \times 2 \mathrm{~cm}$. The second part was applied for microscopic studies (histology). The tissues were fixed in $5 \%$ formal saline solution. The samples were washed, dehydrated in grades of ethyl alcohol, cleared in xylene, embedded in paraffin wax, sectioned at 510 micron and stained with hematoxylin, and eosin, and mounted in Canada balsam according to Carleton (1938).

The thickness of Dermis, Epidermis, Length of Hair bulb (Follicles), Hair, number of sweat glands and sebaceous gland were determined for their morphological changes in the two groups (hair color, texture, length, distribution density). In addition, skin color and texture were recorded. Statistical analyses of data were analyzed using SAS (2000), according to the following model:

$$
\mathbf{Y}_{\mathrm{ij}}=\boldsymbol{\mu}+\mathbf{G}_{\mathrm{i}}+\mathbf{E}_{\mathrm{ij}}
$$

Where:

$$
\begin{aligned}
& \mathrm{Y}_{\mathrm{ij}} \quad \text { : Observation on the } \mathrm{j}^{\text {th }} \text { animals of the } \mathrm{i}^{\text {th }} \text { group, } \\
& \mu \quad: \text { Overall mean, } \\
& \left.\mathrm{G}_{\mathrm{i}} \quad: \text { Fixed effect due to the group (i: } 1=\mathrm{Lab} A \text { and } 2=\mathrm{Lab} B\right), \\
& \mathrm{E}_{\mathrm{ij}} \quad \text { : Random error assumed N.I.D. }\left(0, \sigma^{2} \mathrm{e}\right) .
\end{aligned}
$$




\section{RESULTS AND DISCUSSION}

Table (1) shows the morphological changes of hair and skin due to exposure to the different thermal conditions in lab. Hair color was different between the two experimental groups. Hair color for group $\left(A, 40^{\circ} \mathrm{C}\right)$ was brown to gold, with rough texture, and scattered on the different parts of the abdominal and neck. Roughness and long hair play an important role to increase the performance of distributing heat and sweat of the body to improve the efficiency of circulatory activity of blood underneath the skin. Meanwhile, in group $B\left(25^{\circ} \mathrm{C}\right)$ the hair color was light gray silky with soft texture, short, harmonic on the whole body and thick ( like a piece of marigold). The light skin color in-group ( $A$ ) tended to be red to pink and the body had a wet sebum substance coming from the Holocaine glands. Meanwhile, animals in group (B) had dry dark gray skin with no sebum substance. The secretion of sebum substance fatty layer protects the skin from the high heat temperature and solar radiation, thus increasing the efficiency of the sebaceous and sweat glands to enhance the buffalo efficiency to cope with stress condition. Berman (2003) reported changes in the proportional surface area and hair coat characteristics with advancement of age. In addition, the surface area of the animal is the inter-phase for skin, radiant and evaporative system. The surface area is a component of thermal exchange models (McGovern and Bruce, 2000; Gebremehdin and WU, 2001). It is interesting to find clear accordance between hair, skin and air temperature during seasons and at diurnal times. Shafie and El-Sheikh Aly (1970); Sayah (1997); Ashour et al. (1998); (2004); Omran (1999); Omran (2008); Omran et al. (2011; Omran and Fooda (2012) reported that there were highly significant diurnal and seasonal variations in hair temperature. Riemerschmid and Elder (1945) stated that the temperature of black hair was greater than that of white when cattle were exposed to solar radiation.

Table (2) indicates skin weight, total sample hair weight, hair weight sample, number of hairs by sample and total number of hair by sample for buffalo calves exposed to the two different thermal conditions. All parameters in group $A\left(40{ }^{\circ} \mathrm{C}\right)$, were lower than that of group (B). These results along with the results in Table (1) give potential evidence that the cover of animal plays an important role in acclimation process under any environmental condition this decreased number of hairs under heat stress by 457.5 by $\mathrm{cm}^{2}$ to easily distribute heat to decreased the load of the higher temperature. The morphological characteristics of hair coat are markedly influenced by climate. 
Table 1. Morphological changes of hair $(\mathrm{H})$ and skin $(\mathrm{S})$ of buffalo calves due to exposure to two different thermal artificial conditions at $40^{\circ} \mathrm{C}$ (group A) and $25^{\circ} \mathrm{C}$ (group B ).

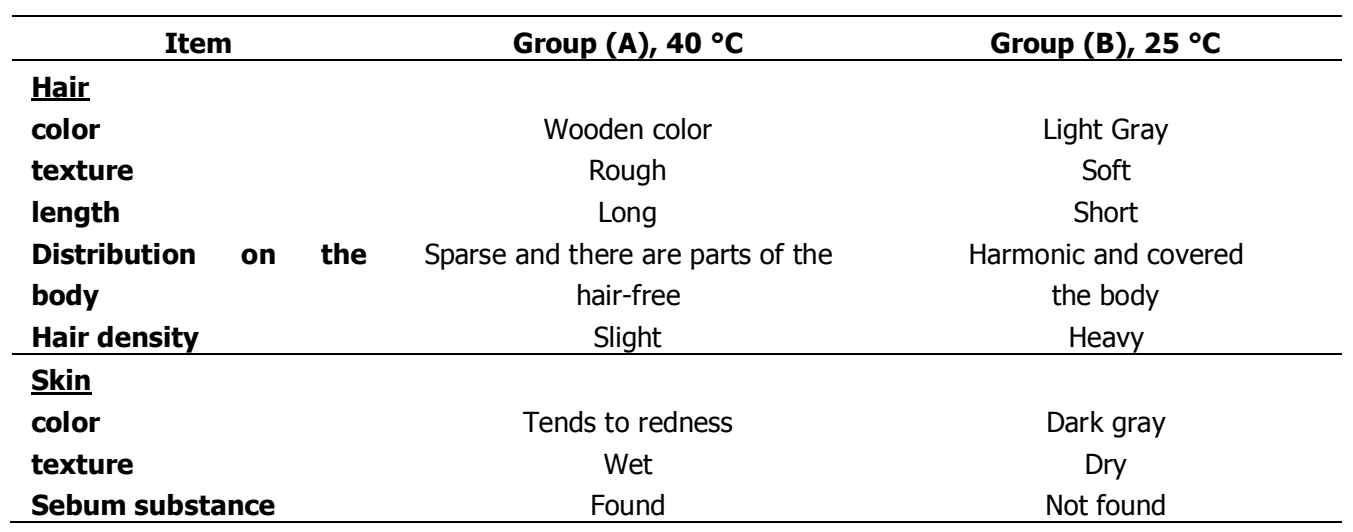

Table 2. Overall means \pm SE of skin weight $(\mathrm{kg})$, total hair sample weight $(\mathrm{g})$, hair weight of part sample $(\mathrm{g})$ and total number of hair per $\mathrm{cm}^{2}$ for sample buffalo calves of the two comparative group.

\begin{tabular}{lcc}
\hline \multicolumn{1}{c}{ Item } & Group $(\mathbf{A}), \mathbf{4 0}^{\circ} \mathbf{C}$ & Group (B), 25 ${ }^{\circ} \mathbf{C}$ \\
\hline Skin weight (kg) & $8.13 \pm 0.72^{\mathrm{b}}$ & $14.75 \pm 0.45^{\mathrm{a}}$ \\
Total hair weight sample (g) & $0.07 \pm 0.005^{\mathrm{b}}$ & $0.10 \pm 0.00^{\mathrm{a}}$ \\
Hair weight of part sample $(\mathbf{g})$ & $0.01 \pm 0.00^{\mathrm{a}}$ & $0.01 \pm 0.00^{\mathrm{a}}$ \\
Total number of hair sample/c & $449.50 \pm 55.10^{\mathrm{b}}$ & $915.00 \pm 1.50^{\mathrm{a}}$ \\
\hline
\end{tabular}

Mean values in the same row with different superscripts are significantly different $(P \leq 0.05)$.

No. of Observation: 36 for each group.

Hafez et al. (1954) found that the average skin thickness was $6.5 \mathrm{~mm}$. in the buffalo calve from ages one to five month. Hafez et al., (1955b) reported that the mean number of hair was 394 in adult buffaloes per sq. $\mathrm{cm}$ and the average thickness of the papillomata's epidermis was $115 \mu$. add to The sebaceous glands and the sweat glands levels were thick in the buffaloes owing to the large size of the glands. In buffaloes, Omran et al., (2018) reported that despite higher estimates of HT and ST were observed for buffaloes and cattle in Lower Egypt compared with those in Middle Egypt, no abundant differences in HT or ST were found between animals in Middle and Upper Egypt. Both species showed increased HT and ST with elevated temperature in the different climates. It was interesting that ST values of buffaloes during winter were relatively higher than that of cattle and greater than the corresponding estimates of other seasons. In the contrary, values of ST in buffaloes during the hot climate were almost similar in all regions. This finding indicated that buffaloes have the potentiality to maintain stability of ST within the different climatic conditions. It is postulated that blood circulation of the host animal plays an important role in this concern. The body coat of an animal plays a major role in adoption and production under different climatic conditions (Hafez et al., 1968). 
Table (3) shows correlation coefficient between body weight and skin weight, total hair sample weight, weight of hair sample, and total number of hair sample. All values were medium and negative correlation in two groups except for skin weight where the correlation was high and positive with group (B) and medium with group (A).

Table 3. Correlation coefficient between body weight with each of skin weight, total of hair weight sample, hair weight of part sample, total number of hair sample and number of hair part samples.

\begin{tabular}{lcc}
\multicolumn{1}{c}{ Item } & Group (A), $40{ }^{\circ} \mathbf{C}$ & Group (B), 25 ${ }^{\circ} \mathbf{C}$ \\
\hline Skin weight $\left(\mathbf{c m}^{\mathbf{2}}\right)$ & $0.63^{* *}$ & $0.93^{* *}$ \\
Total of hair weight sample $\left(\mathbf{c m}^{2}\right)$ & $-0.55^{* *}$ & - \\
Hair weight of part sample $\left(\mathrm{cm}^{2}\right)$ & $-0.55^{* *}$ & - \\
Total number of hair sample/c & & $-0.37^{* *}$ \\
\hline
\end{tabular}

$* *: \mathrm{P} \leq 0.01$

Table (4) shows that, the thickness of epidermis, dermis, total number of hair follicles, length of hair follicles, length of hair, number of sebaceous gland and number of sweat gland for buffalo calves exposed to different thermal conditions $\left(25^{\circ} \mathrm{C}\right.$, $40^{\circ} \mathrm{C}$ ). Significant difference between the two groups for all parameters (except number of sebaceous and sweat gland by filed its fixed genetically $\mu$ ).

Epidermal structures, such as hairs, feathers and scales are highly variable in their growth, readily responding to differences in climate. Enteral stimuli (like thyroid gland) as well as the external stimuli (like season and soil), influence the metabolic activities of the skin. There is annual cycle in the weight, diameter, length, pigmentation and modulation of hair (Hafez et al, 1954).

Skin thickness and papillary layer thickness are smaller in summer than winter, which may be attributed to the accumulation of subcutaneous fat during winter (Hafez et al., 1954). Sweat glands respond in size to ambient temperature, being larger in winter than in summer, while exercise reduces their volume (Dowling and Nay, 1962).

Table 4. Thickness of epidermis $(\mu)$ and Dermis $(\mu)$, total number of hair follicles filed $(\mu)$, length of hair follicles $(\mu)$, length of hair $(\mu)$, number of sebaceous gland filed $(\mu)$ and number of sweat gland filed $(\mu)$ of buffalo calves of the two comparative groups .

\begin{tabular}{lcc}
\hline \multicolumn{1}{c}{ Item } & Group $(\mathbf{A}), \mathbf{4 0}{ }^{\circ} \mathbf{C}$ & Group (B), 25 ${ }^{\circ} \mathbf{C}$ \\
\hline Thickness of epidermis $(\boldsymbol{\mu})$ & $2.09 \pm 0.12 \mathrm{~b}$ & $4.22 \pm 0.16 \mathrm{a}$ \\
Thickness of Dermis $(\boldsymbol{\mu})$ & $90.45 \pm 1.74 \mathrm{~b}$ & $105.05 \pm 2.55 \mathrm{a}$ \\
total number of hair follicles filed $(\boldsymbol{\mu})$ & $3.35 \pm 0.23 \mathrm{~b}$ & $6.47 \pm 1.04 \mathrm{a}$ \\
Length of hair follicles $(\boldsymbol{\mu})$ & $26.0 \pm 1.83 \mathrm{a}$ & $18.36 \pm 0.00 \mathrm{~b}$ \\
Length of hair $(\boldsymbol{\mu} /$ filed) & $9.67 \pm 0.33 \mathrm{a}$ & $3.00 \pm 0.00 \mathrm{~b}$ \\
number of sebaceous gland filed $(\boldsymbol{\mu})$ & $3.38 \pm 0.37 \mathrm{a}$ & $3.50 \pm 0.42 \mathrm{a}$ \\
number of sweat gland filed $(\boldsymbol{\mu})$ & $4.17 \pm 0.60 \mathrm{a}$ & $3.75 \pm 0.48 \mathrm{a}$ \\
\hline
\end{tabular}

Mean values in the same row with different superscripts are significantly different $(P \leq 0.05)$.

No. of Observation: 36 for each group. 
The number of hair follicles varied according to species and body region. The average number per Sq. cm. was 394 (Hafez et al., 1954). Shafie (1958) found that, the sebaceous glands of buffaloes are more highly supplied with blood capillaries than that of cattle. Shafie and Abou El-Khair (1970) found that, sebaceous glands in buffaloes and cattle breeds showed adaptation activity with the variation in seasonal temperature. This sebaceous glands activity coincides well with the other activities related to heat regulation. Sebum secretion varied according to species, breed and month. When the animals being exposed to sun. They showed slight difference in sebum secretion compared to shaded animals (Shafie and Abou El-Khair, 1970). The sweat glands are poorly supplied with blood capillaries as has been demonstrated in Ayrshires cattle, while there is rich supply of sympathetic nerves. The shape of sebaceous sweat glands was different from the stander. As the difference increased the surface area with the blood supply increase. In addition, the changes in all parameters in response to changes in morphology increased the efficiency of buffaloes to climatic variations.

Plates (1,2 a and $b)$ showed increased thickness of epidermis mostly to half , thickness of dermis increased by $14.60(\mu)$, in group (B) compared with group (A). Total of hair follicles number increased in group $B$ than group $A$ by filed $3.11(\mu)$ but the length of hair follicles and length of hair were higher in group $(A)$ compared with group (B) by 7.6, $6.7 \mathrm{~cm}$, respectively (Plate $3 \mathrm{a}$ and b). The difference in the structure between the two groups increased the calf performance in-group $A$ to dissipate of heat stress. The thickness of the skin increases the alarm for the sensory nerves. This in turn increases the speed of skin alarm hypothalamus (central nervous system) to enhance the efficiency of tensor hair leading to increasing blood supply in the surface layer of the skin, which results in speeding of loss the heat from the body. Plate (4) shows the blood supply that was the highest in-group (A) compared to group (B). This can explain the role of the blood vessels on skin surface to increase the efficiency of heat dissipation to decrease the body temperature. (Plates 5 and 6) to increase the activity compared with group $(A)$, the animals do not need increase the blood temperature. Plate (5) shows that the development of sweet, sebaceous glands, where the size of sweet glands and sebaceous glands decreased in group (A) comported with group (B). this development to increase the efficiency the animal with microclimatic condition around them.

Buffalo skin is thick which render active isolative capacity of the bare buffalo skin compared with thinner cattle skin with its hair coat insulation (Hafez et al., 1955b). Shafie (1985) reported arterio-venous arrangement in buffalo skin as effective for circulatory counter current controlling radiation from the body to outside in cold condition or otherwise checking heat inflow into the body in hot condition. 

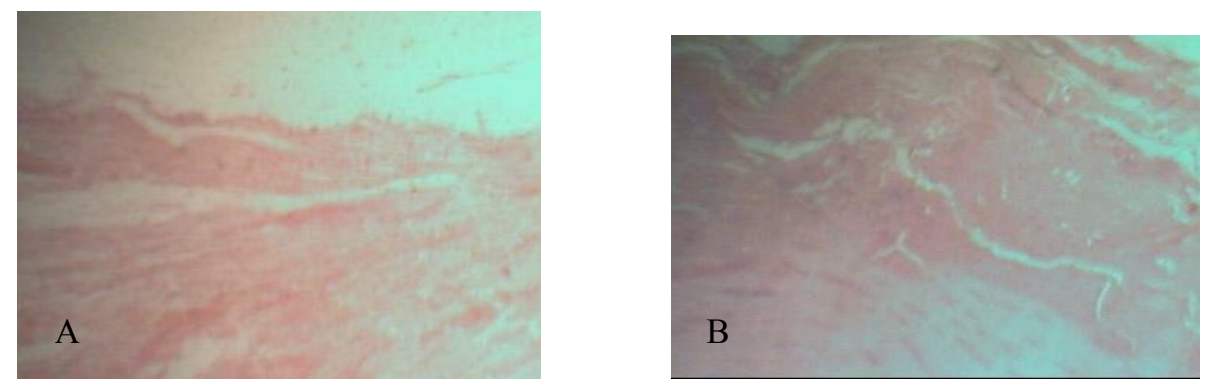

Plat (1). Thickness of epidermis and few part of dermis for buffalo calves under heat stress (A) and under comfort thermal condition (B).
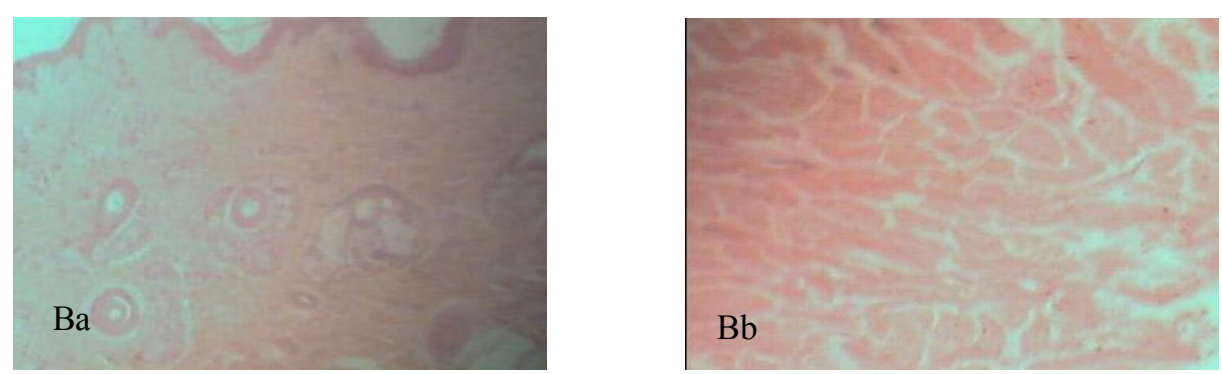

Plat 2. Thickness of epidermis, dermis and blood vessel for buffalo calves under comfort thermal condition ( $\mathrm{Ba}$ and $\mathrm{Bb}$ ).
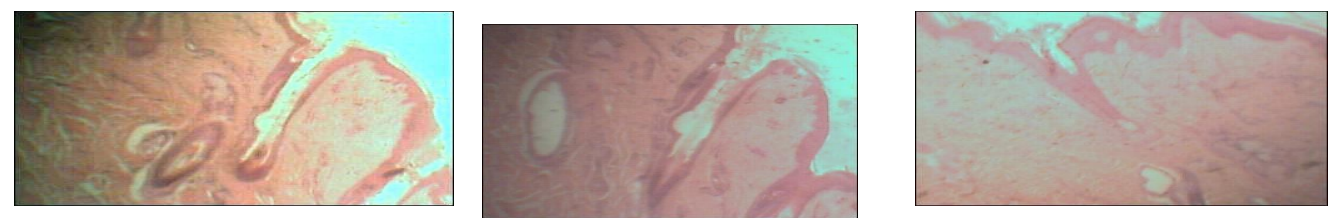

Plat 3. Thickness of epidermis, length of hair follicles and blood vessel under heat stress ( $A a$ and $A b)$ and under comfort thermal condition (B).
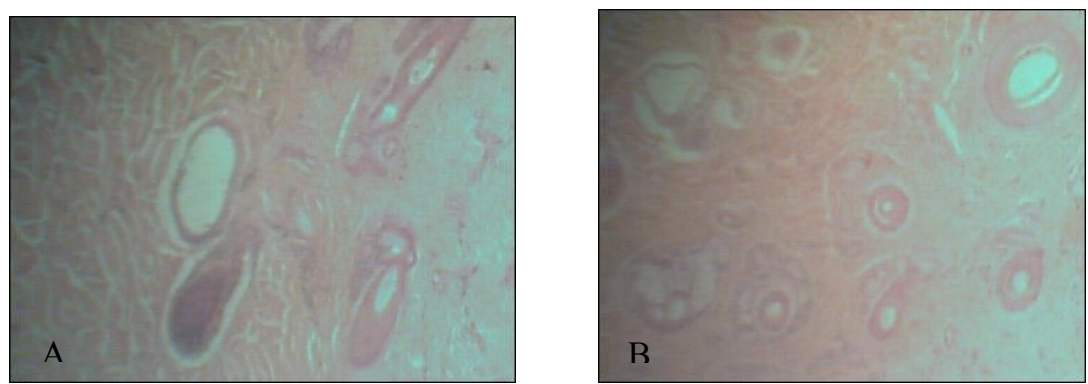

Plat 4. Blood vessel, hair follicles and thickness of dermis for buffalo calves under heat stress $(A)$ and under comfort thermal condition (B). 

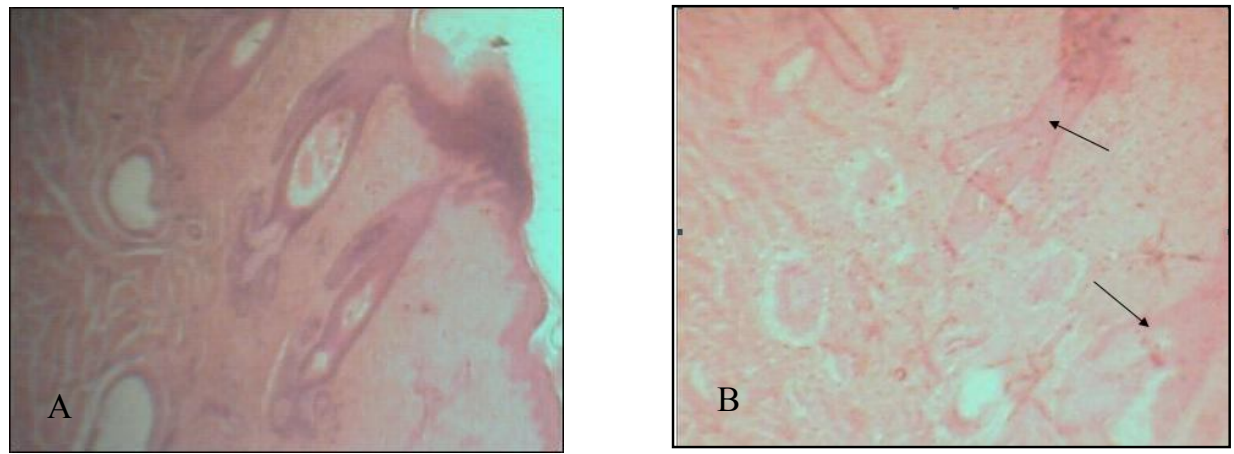

Plate 5. Development of sweet and sebaceous glands, blood vessel and thickness of dermis for buffalo calves under heat stress (A) and under comfort thermal condition (B).
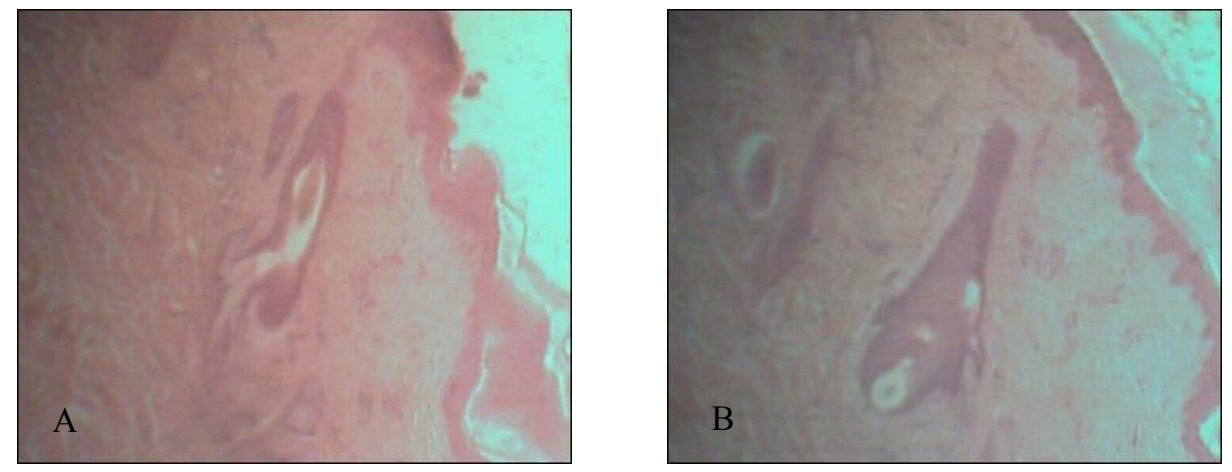

Plate 6. Development of sweet gland, hair follicles, epidermis and dermis layer for buffalo calves under heat stress $(A)$ and under comfort thermal condition (B).

\section{CONCLUSION}

Skin of buffaloes plays important role in adaptation process of this animal to cope with a wide variety of environment. There was negative correlation $(P \leq 0.01)$ between body weight of animal and skin weight but the correlation with hair was mostly positive. The weight of skin relative to the body weight tends to increase the dressing percentage. The buffalo can change the morphology and histology of their skin to maintain bioprocess. There are not any genetic changes for the number of sebaceous or sweet glands. Otherwise, the efficiency for increases by increase in blood supply and nerve simulates. The ability of buffaloes change the thickness of skin, length hair, number of hair follicles, color of hair to make acclamation with any thermal condition to make this animal suitable for different condition. 


\section{REFERENCES}

1. Ashour, G.; S. A. Fawzy; E. A. Omar and M. Omar and M. S. Sayah. 1998. Physiological reactions of weaned Friesian calves in different housing types. Egyptian J. Anim. Prod., 35, Suppl. Issue: 47.

2. Ashour, G.; L. R. Hassan; F. I. Omran and M. M. Shafie. 2004. Thermorespiratory responses hematological and hormonal reactions of buffalo and Friesian calves to the rise in environmental temperature. Egyptian J. Anim. Prod., 41 Suppl. Issue, Nov., 353.

3. Berman, A. 2003. Effects of body surface area estimates on predicted energy requirements and heat stress. J. Dairy Sci., 86: 3605.

4. Carleton, H. M. 1938. Schafer's Essentials OF Histology. Longman, Green And Co., LONDON. NEW YORK. TORONTO.

5. Collier, R. J.; G. E. Dahl and M. J. VanBaale. 2006. Major advances associated with environmental effects on dairy cattle. J. Dairy Sci., 89: 1244-1253.

6. Dowling, D. F. and T. Nay. 1962. Hair follicles and sweat glands of the camel (Camelus dromdarius). Nature, London, 195, 578-580.

7. Gebremehdin, K. G. and B. Wu. 2001. A model of evaporative cooling of wet skin surface and fur layer. J. Thermal Biol., 26: 537.

8. Hafez, E. S. E. 1968. Principles of Animal Adaptation. Ecological and Bioclimatological aspects. Chapter 1, 3-18.

9. Hafez, E. S. E., A. L., Badreldin and M. M., Shafei. 1954. Skin structure of Egyptian buffaloes and cattle with particular reference to sweat glands. Reprinted from J. of Agric. Sci.

10. Hafez, E. S. E., A. L., Badreldin and M. M., Shafei. 1955b. The hair coat in bovine. Empire J. of Exper. Agric., Vol: 23, No. 89

11. McGovern, R. R. and J. M. Bruce. 2000. A model of the thermal balance for cattle in hot conditions. J. Agric. Eng. Res., 77: 81.

12. NRC. 1981. Effect of Environment on Nutrient Requirements of Domestic Animals.ational Academy Press, Washington, DC., USA.

13. Omran, Fayza I. 1999. Physiological reaction and growth performance of buffaloes and Friesian calves to heat stress. M. Sc. Thesis, Fac. Agric., Cairo Univ., Giza, Egypt, P 147.

14. Omran, Fayza I. 2008. Impact of thermo-physiological reaction on growth performance of buffalo calves. Ph. D. Thesis, Fac. Agric., Cairo Univ., Giza, Egypt, P 142.

15. Omran, Fayza I. and T. A. Fooda. 2012. Growth performance and physiological response for buffalo calves under different environmental conditions. Egypt J. Agric. Res., 90(3): 1285-1296. 
16. Omran, Fayza. I.; G. H., Ashour; Laila R. Hassan; M. M. Shafie and M. M. Youssef. 2011. Physiological Responses and Growth Performance of Buffalo and Friesian Calves under Chronic Severe Heat Stress. Proc. of the $4^{\text {th }}$ Animal Wealth Research Conf. in the Middle East \& North Africa, Foreign Agricultural Relations (FAR), Egypt, 3 - 5 October, pp. $01-13$.

17. Omran F. I.; A. A. Khalil and T. A. Fooda. 2018. Physiological responses and hematological aspects of buffaloes and cattles under different climatic conditions in Egypt. Under Publish.

18. Riemerschmid, G. and Elder, J. S. 1945. The absorptivity for solar radiation of different coloured hairy coats of cattle. Onderst, J. Vet. Sci. Snim. Indust., 20, 223-234.

19. SAS. 2002. SAS User's Guide. Statistical Analysis System. Institute, Inc., Cary, NC.

20. Sayah, M. S. 1997. Physiological responses of Feiesian calves to different environmental conditions in Delta region. M.Sc. Thesis, Fac. Agric., Cairo Univ., Giza, Egypt.

21. Shafie, M. M. 1958. Heat regulating mechanism in buffaloes and cattle as affected by hematological values and circulation in skin. Ph. D. Thesis, Fac. Agric., Cairo Univ., Giza, Egypt, 120 PP.

22. Shafie, M. M. 1985. Physiological responses and adaptation of water buffalo. In Stress Physiology In Livestock, Vol. 11, M. K. Yousef (Ed.) Ungulates, CRC, Florida, USA, 67.

23. Shafie, M. M. 1993a. Biological adaptation of buffaloes to climatic conditions. Egyptian J. Anim. Prod., 176.

24. Shafie, M. M. 1993b. Environmental effects on water buffalo production. World Anim. Rev., FAO, 77, 21.

25. Shafie, M. M. and A. M. El-Tannikhy. 1970. Comparative study of skin structure in Egyptian and imported cattle breeds and their crosses in relation to heat tolerance. U. A. R.; J. Anim. Prod., Vol: 10 No. 1, PP. 115-131.

26. Shafie, M. M. and L. El-Sheikh Aly. 1970. Heat tolerance of Friesian cattle under Egyptian climatic conditions. Egyptian J. Anim. Prod., 10: P. 99.

27. Shafie, M. M. and M. M. Abou El-Khair. 1970. Activity of the sebaceous glands of bovines in hot climates. U. A. R. J. Anim. Prod. Vol: 10 No. 1, PP. 81-98.

28. Yeates, N. T. M. 1958. Observations on the role of nutrition in coat shedding in cattle. J. Agric., Sci., 50, 110-112. 


\title{
أقلمة عجول الجاموس تحت الظروف الحرارية المختلفة
}

\author{
محمد محمود الثشافعي ' ، فايزة إبراهيم عمران'
}

$$
\begin{aligned}
& \text { ا ـ قسم الإنتاج الحيواني - كلية الزراعة - جامعة القاهرة - جيزة - مصر }
\end{aligned}
$$

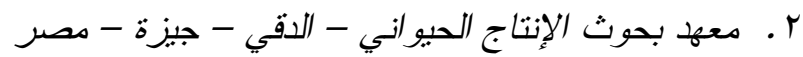

الهدف من هذه الدراسة هو دراسة التغيرات في تركيب الجلد عند التعرض لظروف حرارية مختلفة ودر اسة العلاقة بين تركيب النسيج وطول وكثافة وكفاءة العضلة الثاده للشعر وسمك الجلد،

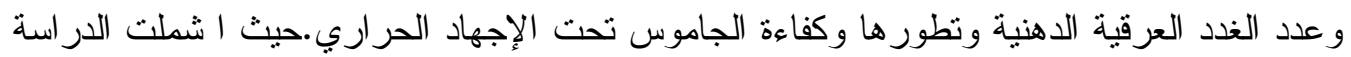

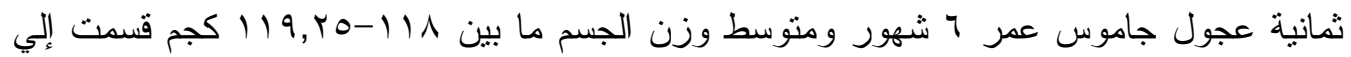

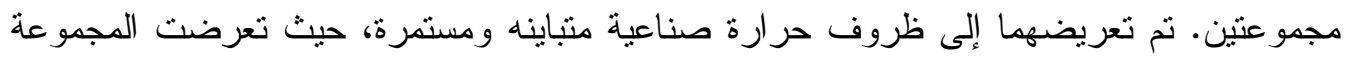

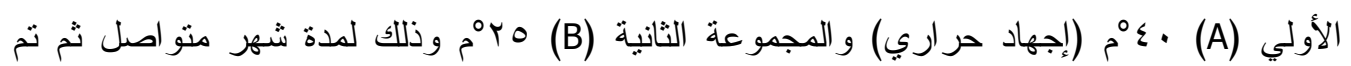

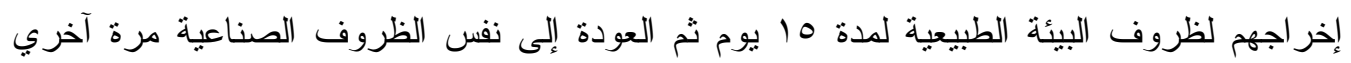
لمدة شهر آخر حيث ظلت الحيوانات تحت نفس الظروف حتى لحظة الذبح. وعند ذبح الحيو انات

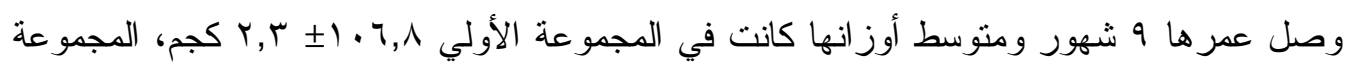

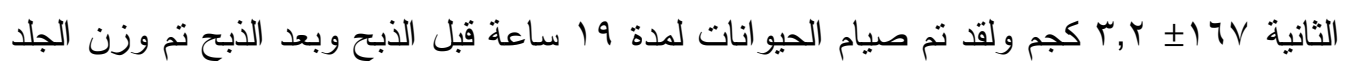
و آخذ عينات من الرقبة والبطن والخلف ونم تقسيمها إلى جزئين، الاول لعمل قطاعات هيستولوجي

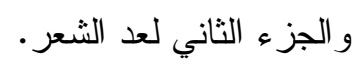
نستخلص من هذه الدراسة، أن الجلد يلعب دور هام في أقلمه الحيوان مع البيئة المحيطة به لهانه

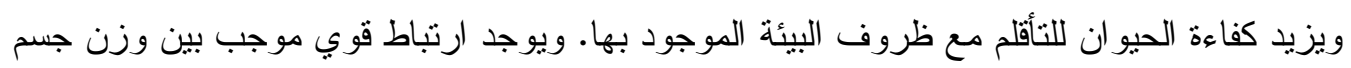

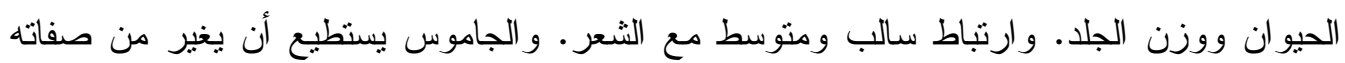

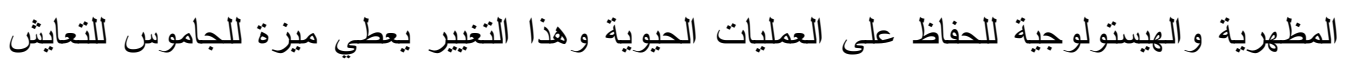
تحت أي ظروف معيشية خاصة مع حدوث التغير ات المناخية التي بدأت بشائر ها حالياً. 